\title{
Impact of Hydrogels on Early Growth of Maize in Sandy Regosols: Progress towards Improving Growth Performance by Enhancing Water and Nutrients Retention Capacity of the Soil
}

\author{
T.S. Rasadaree ${ }^{1}$, H.M.I.K. Herath ${ }^{*}{ }^{1}$, H.T. Dedduwakumara ${ }^{2}$, N. Kottegoda ${ }^{2}$, T. Kuruwita- \\ mudiyanselage ${ }^{3}$
}

\begin{abstract}
Super Absorbent Polymers or hydrogels are known for enhancing the waterholding properties of soils. This experiment was conducted to evaluate the influence of four different locallyproduced hydrogels and one commercially available hydrogel on the early growth of maize in sandy Regosols. Maize variety, Pacific 984 was tested with six treatments in Randomized Complete Block Design. T1 - Reference hydrogel (Sodium polyacrylate-based), T2 - Acrylic acid and acrylamide-based hydrogel where urea has incorporated chemically up to $11.08 \%$
\end{abstract}

${ }^{1}$ Department of Plantation Management, Faculty of Agriculture and Plantation Management, Wayamba University of Sri Lanka, Makandura, Gonawila (NWP), 60170, Sri Lanka.

${ }^{2}$ Department of Chemistry Faculty of Applied Sciences, University of Sri Jayewardenepura, Gangodawila,

Nugegoda, 10250, Sri Lanka

${ }^{3}$ Department of Polymer Science, Faculty of Applied Sciences, University of Sri Jayewardenepura, Gangodawila, Nugegoda, 10250, Sri Lanka

*indikaherath@wyb.ac.lk

https://orcid.org/ 0000-0002-7630-9894

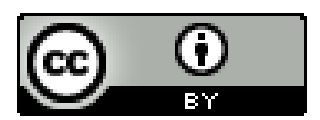

This article is published under the terms of the Creative Commons Attribution 4.0 International License which permits unrestricted use, distribution and reproduction in any medium provided the original author and source are credited. (g/g), T3 - without urea incorporating to the hydrogel used in T2, T4 - similar to T2, but urea incorporated only up to $6.17 \%$ (g/g), T5 - agriculture grade commercial hydrogel (Potassium polyacrylate-based) and T6 - control (without hydrogel) were used for the study. Soil properties and plant growth parameters were quantified. A significant difference was observed in soil $\mathrm{pH}$, total $\mathrm{N}$ and available $\mathrm{P}$ among treatments after one month of application. Treatment 2 showed the highest total $\mathbf{N}$ $(0.19 \%)$ while $T 4$ showed the highest $P$ (18.94 ppm). The highest growth performances were given by locally produced hydrogels over commercial hydrogel and control treatments. Treatment 2 recorded the highest leaf area $\left(\mathbf{1 1 5 3 . 3} \mathrm{cm}^{2} /\right.$ plant$)$, plant height $(\mathbf{1 2 8 . 9 0} \mathrm{cm})$ and total dry mass production $(49.36$ g/plant) while $\mathrm{T} 4$ has recorded the highest stem girth $(4.87 \mathrm{~cm})$. It was observed that locally produced hydrogels including the hydrogel without incorporating urea, have given superior performance over commercial hydrogels. Therefore, it can be concluded that locally produced hydrogel-formulations can enhance the growth of maize effectively than imported commercial hydrogels.

Keywords: Regosols, Super Absorbent Polymers, Water and Nutrients Retention 


\section{INTRODUCTION}

The consequences of climate change on agricultural production are getting aggravated. Food production is in crisis due to prolonged drought conditions in the world with recent climate change (Falkenmark, 2013). Lack or insufficiency of rain for an extended period causes a considerable hydrologic imbalance along with depletion of soil moisture, crop damage, and yield reduction.

Changing precipitation patterns causing a longer dry period has become a dominant factor affecting the agricultural sector in Sri Lanka. Therefore, enhancing water retention in the soil is considered as a vital measure to combat the adverse impact of drought on crop production. Soil water retention is the soil's ability to hold water inside its pores rather than allowing it simply to obey gravity and flow through the soil profile. Soil water retention is a major soil hydraulic property that governs soil functioning in ecosystems and greatly affects soil management for crop production (Rawls et al., 2003). Improved soil water retention capacity also minimizes freshwater resources becoming nutrient-enriched and degraded as a result of pollution from non-point sources. If the moisture content of the soil is optimum for plant growth, plants can readily absorb soil water. Soil water dissolves salts and makes up the soil solution, which is important as a medium for the supply of nutrients to growing plants.

Plants need water and nutrients throughout their life cycle and all aspects of plant development are affected by a reduction in water content in the soil. This reduction in soil moisture leads to changes in the physical environment, which subsequently affect physiological and biochemical processes in plants. Plants respond to moisture stress by reduced height, reduced leaf size, a lesser number of leaves, lowered fruit production and changes in the reproductive phase. Finally, the total crop production will be decreased.

The physical properties of a particular soil determine the amount of water available to the plant in that soil. In coarse sandy soils, it is impossible to store sufficient water in a plantavailable form during irrigation (Banedjschafie and Durner, 2015). Therefore, the farmers who have sandy 
soils, have to irrigate frequently to obtain optimum production.

Kalpitiya in Sri Lanka belongs to the dry zone, receiving an average annual rainfall of $1067 \mathrm{~mm}$. Sandy Regosol is the major soil type in this area. Farmers in Kalpitiya struggles with issues related to less water retention ability in these sandy soils.

Sandy soils have a light texture and loose structure since the particles are large and surrounded by air pockets, which provide plenty of open spaces for water to move through. Therefore, the water does not pool on the surface and drains quickly. As a result, frequent irrigation and nutrient loss have become a severe problem for farmers who cultivate on sandy soils. Therefore, improving water retention in such sandy soil is considered to be very beneficial.

Incorporating organic matter into the soil can be considered as a solution to increase the water holding capacity in sandy soils. However, its applicability is an issue due to the unavailability of organic material in these areas. Besides technical developments to achieve more efficient irrigation, the application of Super
Absorbing Polymers (SAPs) commonly known as hydrogels can be used to improve plant production by enhancing the ability to retain moisture (Banedjschafie and Durner, 2015).

SAPs are a unique group of materials that can absorb over a hundred times their weight in liquids and do not easily release the absorbed fluids under pressure. They can be applied to increase water retention in sandy soils. The addition of SAPs to sandy soil increases the water holding capacity to a considerable amount than when the soil is not treated with SAPs. It has been found that adding SAPs $s$ to the soil matrix increased the water availability for plant use (Yazdani et al., 2007). Polymers consist of molecules having high molar masses and consist of a large number of repeating units. Polymers are formed by chemical reactions containing monomers that are joined sequentially, forming a chain. (Nori and Reddy, 2014). The most important characteristics of these polymers are their ability to absorb water and keep the surrounding area damp and not wet by forming a gel with the polymer (Nori and Reddy, 2014). Commonly used polymers in agriculture are polyacrylamide, polyacrylacid and polyacrylate based 
products. It has been proven that a unit gram of hydrogel can retain 400-1500 gram of water (Woodhouse and Johnson, 1991).

There are many benefits of using Super Absorbent Polymers for sandy soils where water retention is very low. Hydrogels can enhance soil agglomeration and water retention capacity (Yang et al., 2020). Furthermore, previous test results have shown that evaporation losses from soils can be reduced with the use of these hydrogels (Banedjschafie and Durner, 2015). The most significant feature is that they can absorb water up to hundreds to thousands of times than their weight and release it at a slow pace which keeps the plants hydrated for a long time. It also minimizes the loss of nutrients from the soil since applying SAP evenly to the soil of arid areas before irrigation and the rainy season can significantly reduce surface runoff and soil erosion (Yang et al., 2020). As SAP binds to the soil particles, its swell and shrink processes help to control the soil losses (Yang et al., 2020). Globally, there are different types of Super Absorbent Polymers used in the agricultural sector including acrylamide-sodium-acrylate

copolymers, cross-linked polyacrylamides and starchpolyacrylonitrile graft polymers (Abobatta, 2018). However, the outcome and side effects of these materials cannot be assured in different environments. There is a potential risk that these commercially used, imported hydrogels may include pathogens or harmful materials to the local environment. Therefore, it is important if these materials can be produced locally as suit to our local environment, avoiding potential risks associated with imported unsafe materials.

Therefore, this study was carried out with the objective of evaluating the effectiveness of locally produced hydrogels to enhance water holding capacity and plant growth in sandy soils. The potential for use of different hydrogel types was assessed using early growth of maize grown under rain-fed conditions.

\section{MATERIALS AND METHODS}

The experiment was conducted in a protective net house and pots were arranged in a Randomized Complete Block Design with three replicates within three blocks. There were six treatments including the control (Table 1). 
Five hydrogel types with varying compositions were selected for testing (Table 1). They were, Sodium polyacrylate-based hydrogel (T1), Acrylic acid and acrylamide-based hydrogel with incorporated urea (T2 and T4), Acrylamide-based hydrogel without incorporated urea (T3) and a commercially available potassium polyacrylate based hydrogel (T5).

Growing media was prepared using sandy Regosol soil which was collected from the close proximity of Kalpitiya in the North-Western Province of Sri Lanka.

Table 1. Treatments used for the experiment

\begin{tabular}{ll}
\hline Treatment & Composition \\
\hline T1 & Hydrogel type A - Reference hydrogel (sodium polyacrylate based ) \\
T2 & $\begin{array}{l}\text { Hydrogel type B - Acrylic acid and acrylamide based hydrogel where } \\
\text { urea has incorporated chemically up to } 11.08 \%(\mathrm{~g} / \mathrm{g})\end{array}$ \\
T3 & $\begin{array}{l}\text { Hydrogel type C - Acrylic acid and acrylamide based hydrogel without } \\
\text { incorporating urea }\end{array}$ \\
T4 & $\begin{array}{l}\text { Hydrogel type D - Acrylic acid and acrylamide based hydrogel where } \\
\text { urea has incorporated chemically up to } 6.17 \%(\mathrm{~g} / \mathrm{g})\end{array}$ \\
T5 & $\begin{array}{l}\text { Agriculture grade Commercial hydrogel - Potassium polyacrylate based } \\
\text { (imported material) }\end{array}$ \\
T6 & Control - no application of hydrogel
\end{tabular}

Table 2. Fertilizer Recommendation given by DoA for Maize plants (kg per ha)

\begin{tabular}{lccc}
\hline & Urea & MOP & TSP \\
\hline Basal Dressing & 225 & 50 & 100 \\
Top Dressing & 200 & - & - \\
\hline
\end{tabular}


Each pot was filled with $6.5 \mathrm{~kg}$ of airdried soil and ten grams from each type of hydrogel were mixed with soil in T1T5 treatments. The control was only the soil with no hydrogel applied (T6).

After planting the seeds of maize variety, Pacific 984 which were soaked overnight, the fertilizer application was done according to the recommendations of the Department of Agriculture (Table 2) Sri Lanka (Department of Agriculture, 2017) while taking into account the nutrient content in each type of hydrogel.
The spacing of $60 \mathrm{~cm}$ was maintained between two pots within each block (Figure 1). The basal dressing and top dressing of fertilizer were applied two days before planting and one month after planting, respectively. Manual weeding, pest and disease control practices and other cultural practices were done according to the recommendations of the Department of Agriculture, Sri Lanka, providing similar conditions for all treatments.

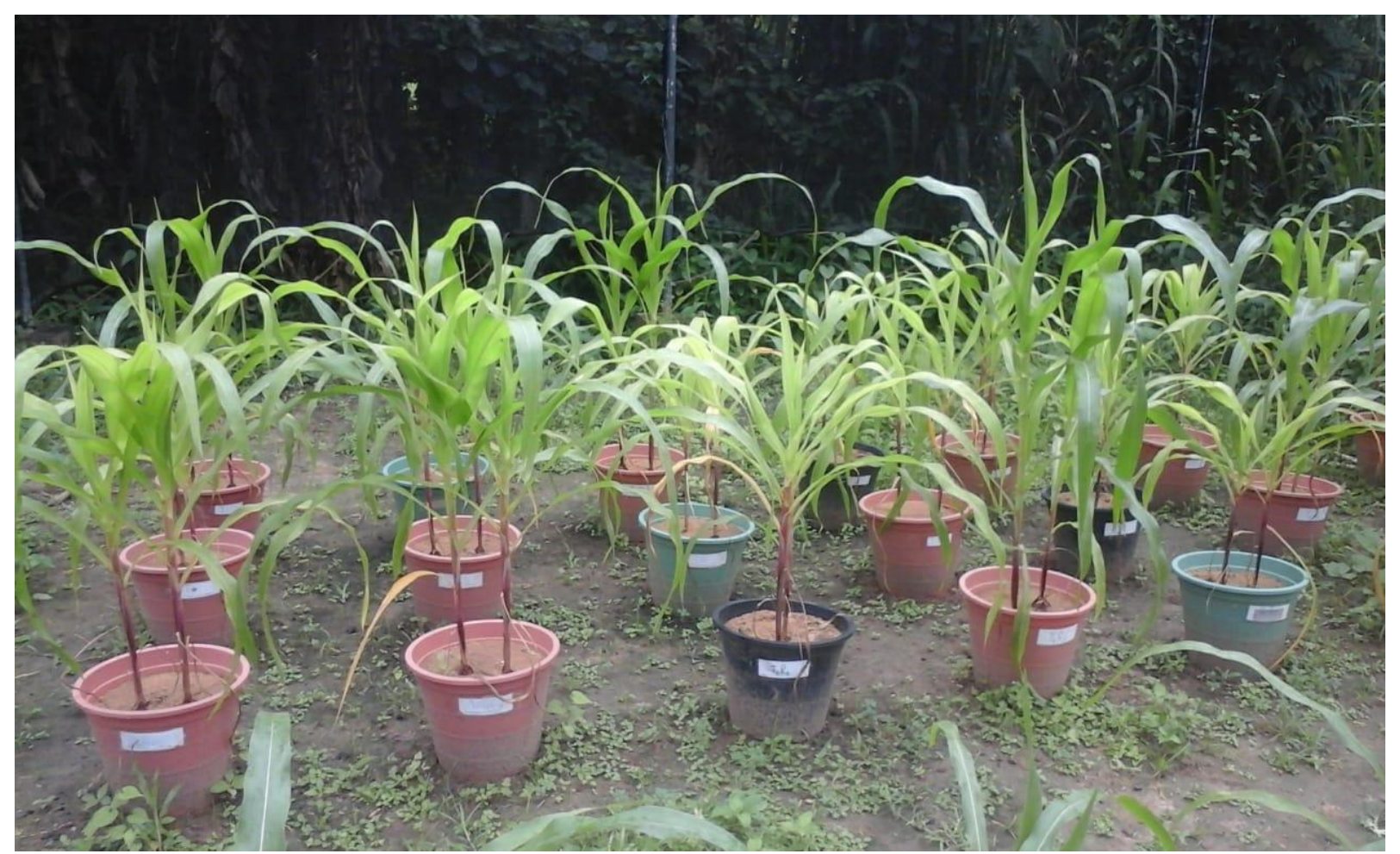

Figure 1. Randomly oriented treated maize plants at 6 weeks after planting 


\section{Sample Collection and Preparation for Chemical Properties}

Composite, representative samples from the bulk soil used for filling pots were taken for initial analysis. For the second analysis, soil samples were collected from three points of a pot approximately $5 \mathrm{~cm}$ away from the base and at the depth of $10-15 \mathrm{~cm}$ of each pot one month after planting before application of the second dose of fertilizer. These samples were air-dried and sieved through a $2 \mathrm{~mm}$ sieve, stored in plastic bags, labeled properly and kept under dry conditions until the analysis was performed. Eighteen samples were taken from all eighteen pots, with three replicates per treatment.

Before analysing for chemical properties, the moisture factor of all soil samples was determined. Moisture content was measured for initial analysis and second analysis separately. About $25 \mathrm{~g}-50 \mathrm{~g}$ from each soil sample were measured into moisture cans and oven-dried at $105{ }^{\circ} \mathrm{C}$ to determine gravimetric water content.

\section{Analysis of Soil Properties}

Soil $\mathrm{pH}$ and Electrical Conductivity were measured by using a glass electrode/pH meter and conductivity meter and cell, respectively. Walkley and Black method (Nelson and Sommers,1982) was applied to determine Soil Organic Carbon as cited in Dharmakeerthi et al. (2007). Total Nitrogen in soil was determined by using the Kjeldahl method (Bremner and Mulvaney, 1982) while the Olsen method (Olsen et al.,1954) was used to quantify the available Phosphorus in the soil as cited in Dharmakeerthi et al. (2007).

\section{Analysis of Plant Growth Parameters}

Plant girth was measured at the height of $45 \mathrm{~cm}$ from the base of the plant by using a measuring tape. Plant height was measured in each plant in treatment using a measuring tape from the base of the plant to the last fully open leaf at two weeks intervals from planting while the number of fully opened leaves was counted per each replicate at two weeks intervals. Leaf area was measured at the end of the experiment (9 weeks after planting) using a leaf area meter (LI-3100C). At the end all stem parts, leaves and roots 
were oven-dried to a constant weight to calculate total biomass production. The Analysis of Variance was conducted to analyse the data using SAS Statistical software (version 9.4).

\section{RESULTS AND DISCUSSION}

\section{Analysis of Soil Properties}

The soil pH level for maize should usually be close to neutral or slightly acidic for better plant growth. This sandy soil had a $\mathrm{pH}$ level of 7.11 before the application of treatments (Table 3 ).
It could be observed that the soil $\mathrm{pH}$ was ranged from 7.23 to 7.53 among treatments and showed a significant difference after one month of treatment application. The lowest $\mathrm{pH}$ was recorded by $\mathrm{T} 1(7.23)$ while the highest $\mathrm{pH}$ was given by control (7.53). All treatments showed an increment in soil $\mathrm{pH}$ compared to the initial status. However, soil pH level was still in the favourable range for maize cultivation (Table 4).

Table 3. Chemical parameters of soils before application of treatments

\begin{tabular}{ll}
\hline \multicolumn{1}{c}{ Soil parameter } & Mean \pm SD \\
\hline $\mathrm{pH}$ & $7.11 \pm 04$ \\
$\mathrm{EC}(\mu \mathrm{s} / \mathrm{cm})$ & $134.3 \pm 0.6$ \\
Total N\% & $0.04 \pm 0.01$ \\
Available $\mathrm{P}(\mathrm{ppm})$ & $39.41 \pm 0.06$ \\
\hline
\end{tabular}

Table 4. Chemical parameters of soils of different treatments after application

\begin{tabular}{lcccc}
\hline Treatment & $\mathbf{p H}$ & $\mathbf{E C}(\boldsymbol{\mu s} / \mathbf{c m})$ & Total N\% & $\begin{array}{c}\text { Available } \mathbf{P} \\
(\mathbf{p p m})\end{array}$ \\
\hline T1 & $7.23^{\mathrm{c}}$ & $68.63^{\mathrm{b}}$ & $0.09^{\mathrm{bc}}$ & $16.52^{\mathrm{ab}}$ \\
T2 & $7.27^{\mathrm{c}}$ & $71.60^{\mathrm{ab}}$ & $0.19^{\mathrm{a}}$ & $13.46^{\mathrm{bcd}}$ \\
T3 & $7.40^{\mathrm{b}}$ & $75.33^{\mathrm{a}}$ & $0.12^{\mathrm{ab}}$ & $11.78^{\mathrm{cd}}$ \\
T4 & $7.49^{\mathrm{ab}}$ & $75.93^{\mathrm{a}}$ & $0.12^{\mathrm{ab}}$ & $18.94^{\mathrm{a}}$ \\
T5 & $7.45^{\mathrm{ab}}$ & $69.73^{\mathrm{ab}}$ & $0.01^{\mathrm{c}}$ & $15.22^{\mathrm{bc}}$ \\
T6 & $7.53^{\mathrm{a}}$ & $72.93^{\mathrm{ab}}$ & $0.04^{\mathrm{bc}}$ & $11.02^{\mathrm{d}}$ \\
\hline$P<0.05$ & 0.0019 & 0.2353 & 0.0268 & 0.0055 \\
\hline Means with different letters within the same column represent significant differences at $P<0.05$ level
\end{tabular}


The EC of soils varies based on the amount of soluble salts present in the soil. Normally, sandy soils have low electrical conductivity whereas clay soils have a high EC (Wiatrak et al., 2009). According to the initial analysis, this sandy soil showed $134.3 \mu \mathrm{s} / \mathrm{cm}$ of EC (Table 3). However, the Electrical Conductivity of soil has been reduced after one month of application. This may be due to the absorption of nutrients from the soil by plants. Electrical conductivity was varied between $68.63(\mu \mathrm{s} / \mathrm{cm})$ to $75.93(\mu \mathrm{s} / \mathrm{cm})$ and the highest EC was given by T4 while the lowest was given by T1 (Table 4). There was no significant difference in EC among treatments when tested after the application of hydrogels.

Nitrogen plays a vital role in plant nutrition. The soil used for the experiment had a very low level of total $\mathrm{N}$ (Table 3) which indicates the importance of supply and retention of nitrogen in this type of soil. The results of the second analysis of soil revealed that Treatment 2 had the highest total Nitrogen content $(0.19 \%)$ compared to other treatments. However, Treatment 5 showed the lowest total nitrogen content one month after application. Treatment 1, 3, 4, and control (T6) have shown an increment in total Nitrogen content compared to the initial status. However, treatment 5 has shown a decreased level of total nitrogen as low as $0.01 \%$ one month after treatment application (Table 4 ).

The results revealed that this soil had a 39.41 ppm of available Phosphorus content before the application of treatments (Table 3). One month after treatment application it showed lower amount of available Phosphorus content than the initial value in all treatments. This may be due to the taking up of Phosphorus by the maize plant. A significant difference could be observed among treatments. Moreover, Treatment 4 showed the highest available Phosphorus content (18.94 ppm) while the lowest was recorded from Treatment 6 which was the control (Table 4). According to Nori and Reddy (2014) and Jorge (2015) SAPs also can absorb fertilizers, pesticides and release them slowly. Thus SAPs can hold nutrients tightly delaying their dissolution thus leaching and runoff of nutrients can be minimized.

\section{Analysis of Growth Parameters}

Plant height is an attribute that is critical to a plant's carbon gain strategy because height is a major determinant 
of a plant's ability to compete for light. The results revealed that Treatment 2 showed the highest plant heights compared to other treatments. However, Treatment which was used commercial hydrogel recorded numerically higher height values closely followed by control. Moreover, the difference was significant among the treatments. All the treatments showed significantly higher plant height than the control (Figure 1 and Table 5).

When considering stem girth, a significant difference could be observed at $9^{\text {th }}$ week. T4 and T2 showed a higher girth while T6 showed the least girth value than all other treatments (Table 5).

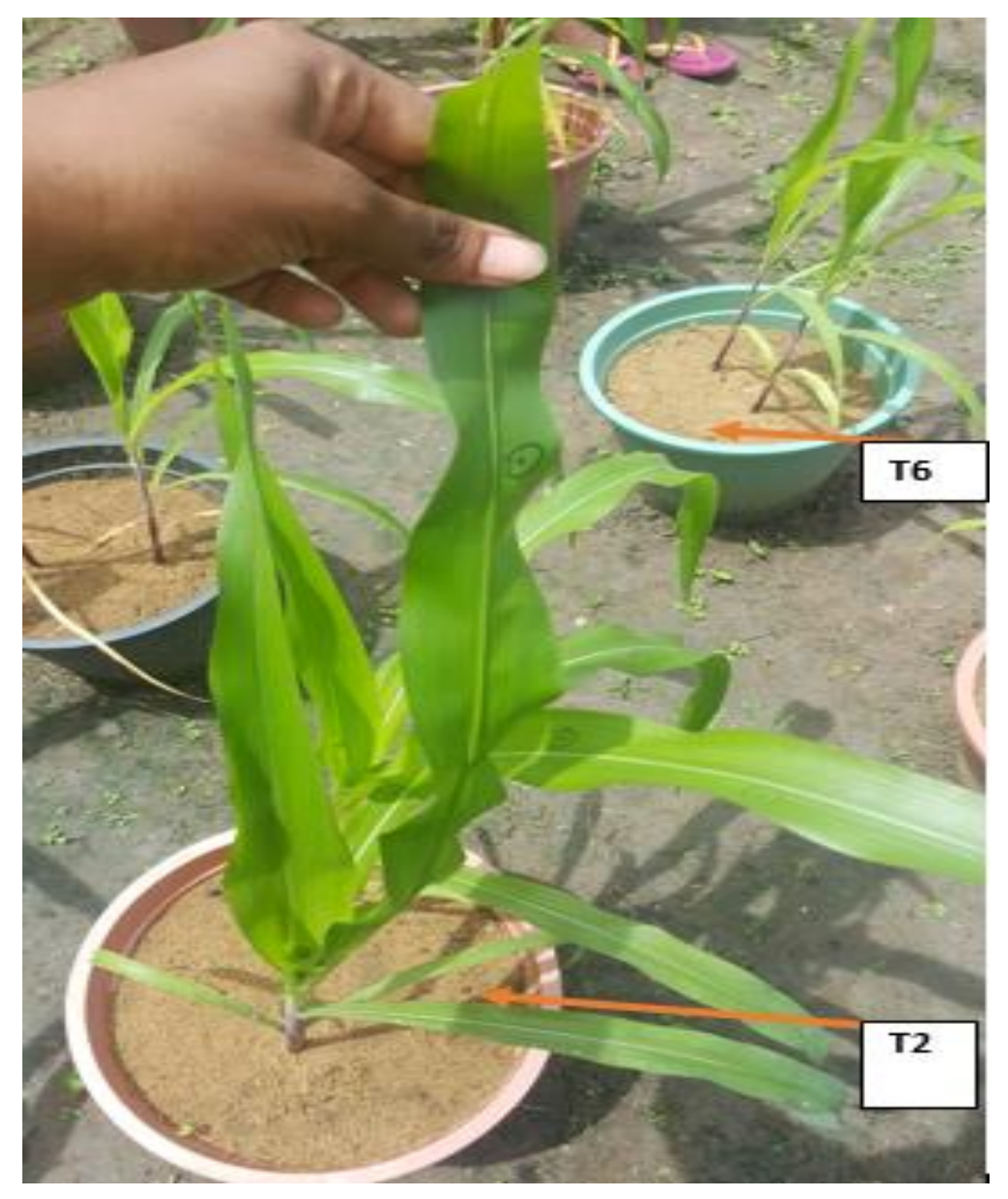

Figure 2. The superior growth performance of T2, compared to control (T6) at four weeks after planting 
Table 5. Vegetative parameters of maize plants under different treatments at $9^{\text {th }}$ week.

\begin{tabular}{lccccc}
\hline Treatment & $\begin{array}{c}\text { Plant height } \\
\mathbf{( c m )}\end{array}$ & $\begin{array}{c}\text { Plant } \\
\text { girth } \\
\mathbf{( c m )}\end{array}$ & $\begin{array}{c}\text { Number of } \\
\text { leaves }\end{array}$ & $\begin{array}{c}\text { Leaf area } \\
\mathbf{( c m}^{\mathbf{2}}\end{array}$ & $\begin{array}{c}\text { Total dry } \\
\text { mass } \\
\text { production } \\
\mathbf{( g )}\end{array}$ \\
\hline T1 & $110.77^{\mathrm{abc}}$ & $3.77^{\mathrm{bc}}$ & $16.33^{\mathrm{ab}}$ & $699.7^{\mathrm{b}}$ & $19.267^{\mathrm{c}}$ \\
T2 & $128.90^{\mathrm{a}}$ & $4.57^{\mathrm{ab}}$ & $15.67^{\mathrm{ab}}$ & $1153.3^{\mathrm{a}}$ & $49.355^{\mathrm{a}}$ \\
T3 & $103.70^{\mathrm{bc}}$ & $4.37^{\mathrm{abc}}$ & $16.83^{\mathrm{a}}$ & $775.5^{\mathrm{b}}$ & $28.543^{\mathrm{b}}$ \\
T4 & $124.97^{\mathrm{ab}}$ & $4.87^{\mathrm{a}}$ & $16.33^{\mathrm{a}}$ & $1018.3^{\mathrm{a}}$ & $34.017^{\mathrm{b}}$ \\
T5 & $91.93^{\mathrm{cd}}$ & $3.40^{\mathrm{cd}}$ & $15.67^{\mathrm{ab}}$ & $444.7^{\mathrm{c}}$ & $15.195^{\mathrm{c}}$ \\
T6 & $79.57^{\mathrm{d}}$ & $2.70^{\mathrm{d}}$ & $15.33^{\mathrm{b}}$ & $444.7^{\mathrm{c}}$ & $14.445^{\mathrm{c}}$ \\
\hline$P<0.05$ & 0.0022 & 0.008 & 0.1691 & 0.0005 & $.0001^{2}$ \\
\hline
\end{tabular}

Means with different letters within the same column represent significant differences at $P<0.05$ level

There have been similar results reported in a study mixing soil with hydrogel-loaded fertilizers that improved the growth of maize plants (Rahman et al. 2001). The number of leaves per plant is another important development parameter that can be considered as an indicator of plant growth. According to the results, there was no significant difference among treatments in the number of leaves. However, the highest number of leaves were recorded from Treatment 3 while the control showed the lowest number of leaves compared to others (Table 5).

When leaf area increases, it tends to intercept more light and it enhances the photosynthetic potential (Weraduwage et al., 2015). According to the results, Treatment 2 (Figure 2) and Treatment 4 showed leaf area than other treatments. However, Treatment 5 and control accounted for the lowest leaf areas (Table 5).

When considering the plant dry matter, the highest mean value of the total dry mass production (49.36 g) was observed in T2. The dry matter content in $\mathrm{T} 2$ and $\mathrm{T} 4$ was significantly higher than in others. T6 showed the lowest mean value (Table 5). In T3 treatment which was only the hydrogel without incorporating urea, all growth parameters were in the high range 
compared to the control treatment (T6), indicating the potential of locally produced hydrogel in enhancing the crop growth. When the plant height, stem girth and the number of leaves increase the productivity of crops generally increases. The results indicate that the application of SAPs has significantly enhanced the plant growth through conditioning the soil and retaining soil nutrients.

\section{CONCLUSION}

Results revealed that when hydrogels are applied to the soils, they have the potential for conditioning the soil and supporting crop growth. The locally produced hydrogels have retained more total Nitrogen, soil available Phosphorus, and also increased the $\mathrm{pH}$ and EC levels than those of commercial hydrogels in the tested sandy soil.

According to the results, locally produced hydrogel types B and D have given superior performances over commercial hydrogels relevant to plant height, stem girth, leaf area and total dry mass production. Therefore, it can be concluded that locally developed acrylic acid and acrylamide-based hydrogel formulations used in T2 and
T4 can effectively be used in enhancing the growth of maize in sandy Regosols.

\section{ACKNOWLEDGEMENT}

The authors wish to acknowledge the 'Accelerating Higher Education Expansion and Development (AHEAD)' DOR No.51 (STEM) Grant (No 6026-LK/8743-LK) for giving the financial assistance for the study.

\section{REFERENCES}

Abobatta W. (2018). Impact of hydrogel polymer in agricultural sector. Advances in Agriculture and Environmental Science, 1(2): 59-64. DOI: 10.30881/aaeoa.00011

Banedjschafie, S., and Durner, W. (2015). Water retention properties of a sandy soil with superabsorbent polymers as affected by aging and water quality. Journal of Plant Nutrition and Soil Science, 178(5): 798806.

Bremner J. M, and Mulvaney C.S. (1982). Nitrogen-total. In A. L. Page, R. H. Miller, D. R. Keeney (Eds.), Methods of soil analysis-Part 2, Chemical and Microbiological Properties (pp. 595-624.). Soil Science Society of America: Madison, WI, USA.

Department of Agriculture. (2017). Available from: https://www.doa.gov.lk/FCRDI/ind 
ex.php/en/crop/43-maize-e

(Accessed 25.10.2020).

Dharmakeerthi, R.S., Indraratne, S.P. and Kumaragamage, D. (2007). Manual of soil sampling and analysis. Soil Science Society of Sri Lanka, Peradeniya, Sri Lankka, pp.57-61.

Falkenmark, M. (2013). Growing water scarcity in agriculture: future challenge to global water security. Mathematical, Physical and Engineering Sciences, 371(2002): 20120410.

Jorge, S.G. (2015). Characterization and effects of cross-linked potassium polyacrylate as soil amendment. Doctoral dissertation, University of Seville.

Nelson, D. W. and Sommers, L.E. (1982). Total carbon, organic carbon, and organic matter. Methods of soil analysis part 3. Soil Science Society of America: Madison, WI, USA, pp. 961-1010.

Nori, J. M. and Reddy, R. L. (2014). Powdered Water-A Compact Solution for Drought Stricken Farms. International Journal of Current Engineering and Technology, 4(4): 1-4.

Olsen, S. R., Cole, C. V., Watanabe, F. S. and Dean, L.A. (1954). Estimation of available phosphorus in soils by extraction with sodium bicarbonate. Circular, United States Department of Agriculture; Washington. p. 939

Rahman, M. S., Sarke,r A. M. and Islam, M. S. (2001). Effect of soil moisture on grain yield of wheat (Triticum aestivum L) cultivars. Environment and Ecology, 19(2): 304-308.

Rawls, W. J., Pachepsky, Y. A., Ritchie, J. C., Sobecki, T. M., and Bloodworth, H. (2003). Effect of soil organic carbon on soil water retention. Geoderma, 116(1-2): 61-76.

Weraduwage, S. M., Chen, J., Anozie, F. C., Morales, A., Weise, S. E., and Sharkey, T. D. (2015). The relationship between leaf area growth and biomass accumulation in Arabidopsis thaliana. Frontiers in Plant Science, 6: 167.

Wiatrak, P., Khalilian, A., Mueller, J., and Henderson, W. (2009). Applications of soil electrical conductivity in production agriculture. Better Crops, 93(2): 1617.

Woodhouse, J. and Johnson, M. S. (1991). Effect of superabsorbent polymers on survival and growth of crop seedlings. Agricultural Water Management, 20(1): 63-70.

Yang, F., Cen, R., Feng, W., Liu, J., Qu, Z., and Miao, Q. (2020). Effects of super-absorbent polymer on soil remediation and crop growth in arid and semi-arid areas. Sustainability, 12(18): 7825.

Yazdani, F., Allahdadi, I., and Akbari, G. A. (2007). Impact of superabsorbent polymer on yield and growth analysis of soybean (Glycine max L.) under drought stress condition. Pakistan Journal of Biological Sciences (PJBS), 10(23): 4190-4196. 